Author affiliations appear at the end of this article.

tDeceased

Published online ahead of print at www.jco.org on July 11, 2016.

Supported in Italy by the Gruppo Italiano Malattie Ematologiche dell'Adulto Foundation; the Associazione Italiana Contro le Leucemie, Linfomi e Mieloma: and, for molecular analyses, the Associazione Italiana per la Ricerca sul Cancro (Grant No. IG 5916 to F.L.-C.). Supported in Germany by the Federal Ministry of Education and Research (Grant No. FKZ 01KG0903 to U.P.).

Presented in part at the 56th Annual Congress of the American Society of Hematology, San Francisco, CA

December 6-9, 2014.

Authors' disclosures of potential conflicts of interest are found in the article online at www.jco.org. Author contributions are found at the end of this article.

Clinical trial information: NCT00482833.

Corresponding author: Francesco

Lo-Coco, MD, Department of

Biomedicine and Prevention, University

Tor Vergata, Via Montpellier 1, Rome

00133, Italy; e-mail; francesco.lo.coco@

uniroma2.it.

(c) 2016 by American Society of Clinical Oncology

0732-183X/16/3499-1/\$20.00

DOI: 10.1200/JCO.2016.67.1982

\title{
Improved Outcomes With Retinoic Acid and Arsenic Trioxide Compared With Retinoic Acid and Chemotherapy in Non-High-Risk Acute Promyelocytic Leukemia: Final Results of the Randomized Italian-German APL0406 Trial
}

Uwe Platzbecker, Giuseppe Avvisati, Laura Cicconi, Christian Thiede, Francesca Paoloni, Marco Vignetti, Felicetto Ferrara, Mariadomenica Divona, Francesco Albano, Fabio Efficace, Paola Fazi, Marco Sborgia, Eros Di Bona, Massimo Breccia, Erika Borlenghi, Roberto Cairoli, Alessandro Rambaldi, Lorella Melillo, Giorgio La Nasa, Walter Fiedler, Peter Brossart, Bernd Hertenstein, Helmut R. Salih, Mohammed Wattad, Michael Lübbert, Christian H. Brandts, Mathias Hänel, Christoph Röllig, Norbert Schmitz, Hartmut Link, Chiara Frairia, Enrico Maria Pogliani, † Claudio Fozza, Alfonso Maria D’Arco, Nicola Di Renzo, Agostino Cortelezzi, Francesco Fabbiano, Konstanze Döhner, Arnold Ganser, Hartmut Döhner, Sergio Amadori, Franco Mandelli, Gerhard Ehninger, Richard F. Schlenk, and Francesco Lo-Coco

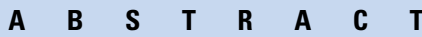

\section{Purpose}

The initial results of the APL0406 trial showed that the combination of all-trans-retinoic acid (ATRA) and arsenic trioxide (ATO) is at least not inferior to standard ATRA and chemotherapy (CHT) in firstline therapy of low- or intermediate-risk acute promyelocytic leukemia (APL). We herein report the final analysis on the complete series of patients enrolled onto this trial.

\section{Patients and Methods}

The APL0406 study was a prospective, randomized, multicenter, open-label, phase III noninferiority trial. Eligible patients were adults between 18 and 71 years of age with newly diagnosed, low- or intermediate-risk APL (WBC at diagnosis $\leq 10 \times 10^{9} / \mathrm{L}$ ). Overall, 276 patients were randomly assigned to receive ATRA-ATO or ATRA-CHT between October 2007 and January 2013.

\section{Results}

Of 263 patients evaluable for response to induction, 127 (100\%) of 127 patients and 132 (97\%) of 136 patients achieved complete remission (CR) in the ATRA-ATO and ATRA-CHT arms, respectively $(P=.12)$. After a median follow-up of $\mathbf{4 0 . 6}$ months, the event-free survival, cumulative incidence of relapse, and overall survival at 50 months for patients in the ATRA-ATO versus ATRA-CHT arms were $97.3 \% v 80 \%$, $1.9 \% \vee 13.9 \%$, and $99.2 \% \vee 92.6 \%$, respectively $(P<.001, P=.0013$, and $P=.0073$, respectively). Postinduction events included two relapses and one death in CR in the ATRA-ATO arm and two instances of molecular resistance after third consolidation, 15 relapses, and five deaths in CR in the ATRACHT arm. Two patients in the ATRA-CHT arm developed a therapy-related myeloid neoplasm.

\section{Conclusion}

These results show that the advantages of ATRA-ATO over ATRA-CHT increase over time and that there is significantly greater and more sustained antileukemic efficacy of ATO-ATRA compared with ATRA-CHT in low- and intermediate-risk APL.

\section{J Clin Oncol 34. (C) 2016 by American Society of Clinical Oncology}

\section{INTRODUCTION}

Standard therapy of acute promyelocytic leukemia (APL) has long since relied on the combination of all-trans-retinoic acid (ATRA) and chemotherapy (CHT). Despite providing high cure rates, this approach is associated with frequent severe hematologic toxicity and development of secondary myeloid neoplasms in approximately $2 \%$ of patients. ${ }^{1-11}$ The introduction of arsenic trioxide (ATO) in APL treatment has resulted in similarly high remission and survival rates coupled with significantly reduced myelosuppression. ATO is currently regarded as the most effective single agent in APL and is licensed for the treatment of relapsed and refractory APL. ${ }^{12-15}$ 
Recently, CHT-free regimens based on ATO with or without ATRA have proven highly effective in newly diagnosed APL. ${ }^{16-19}$ After pilot studies suggesting that ATRA plus ATO could substitute the standard approach in the treatment of newly diagnosed disease, ${ }^{18,19}$ two large independent randomized trials reported significantly improved outcomes for patients treated with ATRAATO compared with those receiving ATRA-CHT. ${ }^{20,21}$ On the basis of these data, expert panels from the United States and Canada have indicated ATRA-ATO as the favored option in first-line therapy of non-high-risk APL. ${ }^{22,23}$

The APL0406 randomized trial reported by the Gruppo Italiano per le Malattie Ematologiche dell'Adulto (GIMEMA), Acute Myeloid Leukemia Study Group (AMLSG), and Study Alliance Leukemia (SAL) showed in the initial series of 156 patients that ATO-ATRA is at least not inferior, and probably superior, to standard ATRA-CHT for patients with newly diagnosed, nonhigh-risk APL. ${ }^{20}$ We herein report the results of this study after a more prolonged follow-up and including the extended and final series of patients who were randomly assigned to receive ATRAATO or ATRA-CHT.

\section{PATIENTS AND METHODS}

\section{Study Design and Patients}

The APL0406 study was a prospective, randomized, multicenter, open-label, phase III noninferiority trial. The study was designed by GIMEMA in April 2006 (APL0406); it was started in Italy in October 2007 and was joined in 2008 by the German SAL and AMLSG groups. The study was designed to show that the ATRA-ATO regimen is not inferior to the ATRA-CHT regimen in terms of event-free survival (EFS) rate at 2 years. The full trial design and the results obtained in the initial series of 156 patients were reported in $2013 .{ }^{20}$ Briefly, eligible patients were adults age 18 to 71 years with newly diagnosed, low- or intermediate-risk APL (WBC at diagnosis $\left.\leq 10 \times 10^{9} / \mathrm{L}\right)$. Initial patient enrollment and random assignment were based on the sole morphologic diagnosis of APL according to the French-American-British criteria. Random assignment was stratified by institutions; random block size was four.

Genetic diagnostic confirmation was mandatory for eligibility and was carried out through centralized reference laboratories in Italy and Germany (F.L.-C., Università Tor Vergata in Rome, Italy, for GIMEMA and C.T., Carl Gustav Carus Universitätsklinikum in Dresden, Germany, for SAL and AMLSG). The trial was conducted in accordance with the Declaration of Helsinki, received institutional review board approval by all participating centers, and was registered at ClinicalTrials.gov (identifier: NCT00482833).

In September 2010, the study reached the initially programmed accrual of 162 patients and enrollment was suspended. At the time of inclusion of the last patient, however, compliance with quality-of-life (QoL) questionnaires was lower than initially anticipated. Therefore, considering QoL was a key secondary objective of the trial, the study was amended and restarted in March 2011 in an effort to maximize information obtained regarding burden of disease and treatment effects over time from patients themselves. The new target accrual to meet the QoL objective was set to 276 patients. The amendment was approved by all ethical committees of participating centers, and all patients provided written informed consent. A list of authors and centers that contributed to the APL0406 trial can be found in the Appendix (online only).

\section{Treatment Arms, Supportive Measures, and Management of Complications}

The treatment schedules for the ATRA-ATO and ATRA-CHT regimens, the recommended supportive measures to prevent and treat the APL- associated coagulopathy and differentiation syndrome (DS), and the management of major expected therapy-related complications (QTc prolongation, hyperleukocytosis, and hepatotoxicity) have been reported in detail. ${ }^{20}$ In particular, prednisone prophylaxis $(0.5 \mathrm{mg} / \mathrm{kg}$ daily) was administered during the entire remission induction phase to prevent DS. Hydroxyurea was the only cytotoxic agent allowed to control hyperleukocytosis. Finally, temporary discontinuation and dose adjustments were recommended to manage ATO nonhematologic toxicity, as detailed elsewhere. ${ }^{20}$

\section{Laboratory Studies}

Genetic studies, including reverse transcriptase polymerase chain reaction (RT-PCR) amplification of the PML-RARA hybrid using standardized protocols, were mandatory at diagnosis and after the third consolidation for all patients enrolled onto the study. Furthermore, longitudinal prospective monitoring of minimal residual disease was assessed by nested RT-PCR and quantitative RT-PCR in marrow samples for patients in both arms after induction therapy (for investigational purposes only) and during follow-up. Molecular studies also included fms-like tyrosine kinase 3 (FLT3) mutational status for the presence of the internal tandem duplication.

\section{Outcomes}

The primary study objective was to compare EFS at 2 years from diagnosis between the two treatment arms. Treatment failure was defined as any of the following events: no achievement of hematologic complete remission (HCR) after induction therapy, no achievement of molecular complete remission (CR) after three consolidation courses, relapse (molecular or hematologic, whichever was detected first), and death.

Secondary end points included rate of HCR after induction, overall survival (OS) at 2 years, disease-free survival (DFS), cumulative incidence of relapse (CIR, defined as the time from HCR achievement to either molecular or hematologic relapse, whichever was detected first), incidence and severity of hematologic and nonhematologic toxic episodes during treatment (graded according to National Cancer Institute Common Terminology Criteria for Adverse Events), kinetics of minimal residual disease, and self-assessed QoL.

OS was defined as the time from diagnosis to death from any cause. DFS was defined as the time from HCR achievement to relapse (either molecular or hematologic), persistence of polymerase chain reaction (PCR) positivity after consolidation, death, or date of last follow-up for patients alive in first molecular CR. Induction death was defined as death occurring at any time during induction therapy, before the achievement of HCR. CIR was calculated from the date of HCR until first relapse (either molecular or hematologic relapse) considering death in $\mathrm{CR}$ as a competing risk.

\section{Statistical Analysis}

All patients enrolled onto the study were analyzed following an intentto-treat principle. Characteristics of patients were summarized by crosstabulations (categorical variables) and quantiles (eg, median; for continuous variables). Nonparametric tests were applied for comparisons between groups ( $\chi^{2}$ and Fisher's exact test for categorical variables; Mann-Whitney $U$ test and Kruskal-Wallis test for continuous variables). Survival distributions (OS, EFS, and DFS) were estimated using the Kaplan-Meier method. CIR was calculated using the proper nonparametric method. Differences in terms of OS, EFS, and DFS were evaluated using the log-rank test. The Gray test was applied to compare cumulative incidence curves. All tests were two-sided.

\section{RESULTS}

\section{Enrollment and Patient Characteristics}

The enrollment period was from October 2007 to January 2013. A total of 276 patients with low- or intermediate-risk APL were randomly assigned. Genetic tests excluded PML-RARApositive APL in six patients (five patients randomly assigned to 
ATRA-ATO and one randomly assigned to ATRA-CHT). Of the remaining 270 patients, four patients did not start allocated treatment (two treatment refusals, both in the ATRA-CHT arm, and two major violations, both in the ATRA-ATO arm). Therefore, 266 patients (129 randomly assigned to ATRA-ATO and 137 randomly assigned to ATRA-CHT) were included in the intent-totreat analysis. The disposition of the patients and reasons for exclusion are shown in Figure 1.

The main demographic, clinical, and laboratory features of the 266 patients eligible for analysis are listed in Table 1 . There were no significant differences in the baseline characteristics between the two cohorts. The present analysis was performed in December 2015 with a median follow-up time of 40.6 months (range, 0.1 to 83.6 months).

\section{Induction Therapy}

Four patients died during induction in the ATRA-CHT group. The causes of death were DS $(n=2)$, ischemic stroke $(n=1)$, and bronchopneumonia $(n=1)$. All deaths were recorded in the initial series, ${ }^{20}$ and no further deaths occurred in the second cohort of 110 patients enrolled in the postamendment period from March 2011 to January 2013. One hundred twenty-seven patients in the ATRAATO arm and 136 patients in the ATRA-CHT arm were evaluable for induction response. HCR was documented in 127 patients $(100 \%)$ and 132 patients (97\%) in the ATRA-ATO and ATRA-CHT arms, respectively $(P=.12)$. For two patients who started induction in the ATRA-ATO arm, the assigned treatment was terminated early. For one of these patients, a protocol violation occurred (early evaluation of bone marrow aspirate at day +13 with inappropriate diagnosis of resistant disease). This patient was alive at 2 years from diagnosis. In the other patient, treatment was permanently withdrawn by the treating physician as a result of toxicity (QTC prolongation and electrolyte abnormalities at day +3 ), and the patient was lost to follow-up. In one patient in the ATRA-CHT arm, treatment was discontinued as a result of an unknown reason, and the patient was lost to follow-up.

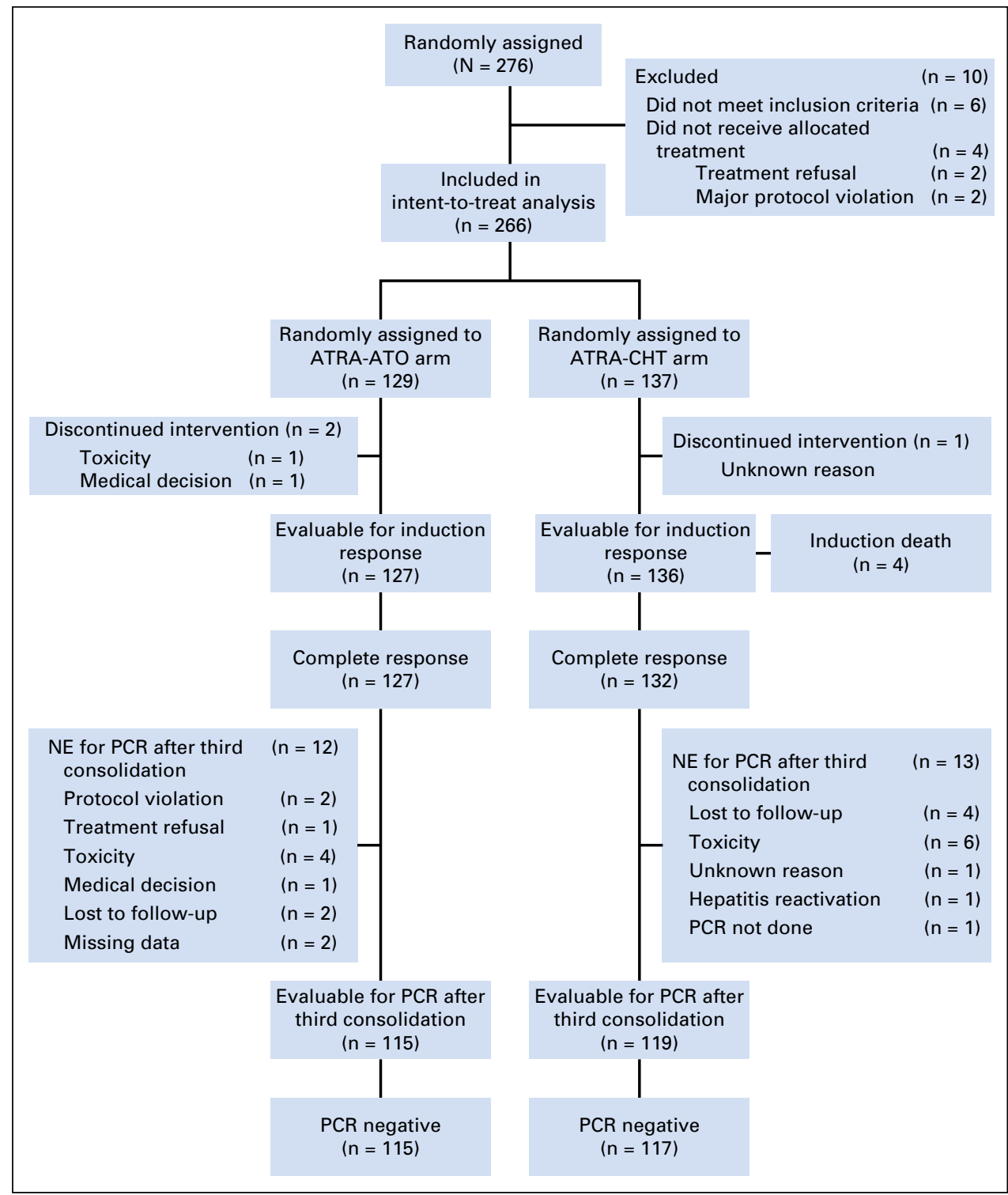

Fig 1. Study enrollment, random assignment, and retention. ATO, arsenic trioxide; ATRA, all-trans-retinoic acid; CHT, chemotherapy; NE, not evaluable; PCR, polymerase chain reaction. 


\begin{tabular}{|c|c|c|c|}
\hline Characteristic & $\begin{array}{c}\text { ATRA-ATO } \\
(\mathrm{n}=129)\end{array}$ & $\begin{array}{c}\text { ATRA-CHT } \\
(\mathrm{n}=137)\end{array}$ & $P$ \\
\hline Median age, years (range) & $46.6(18.8-70.2)$ & $46.6(18-70.3)$ & .84 \\
\hline Sex, No. (\%) & & & .45 \\
\hline Male & $60(46.5)$ & $70(51.1)$ & \\
\hline Female & $69(53.5)$ & 67 (48.9) & \\
\hline Median WBC, × 109/L (range) & $1.4(0.32-10)$ & $1.5(0.3-9.61)$ & .83 \\
\hline Median platelets, $\times 10^{9} / \mathrm{L}$ (range) & $36.5(3-224)$ & $31.5(3-236)$ & .19 \\
\hline Sanz risk, No. (\%) & & & .52 \\
\hline Low & $57(45.2)$ & 55 (41.3) & \\
\hline Intermediate & $69(54.7)$ & 78 (58.6) & \\
\hline PML-RARA isoform, No. (\%) & & & .35 \\
\hline Long & $83(68.6)$ & 78 (62.9) & \\
\hline Short & 38 (31.4) & $46(37.1)$ & \\
\hline Missing & $8(7)$ & $13(10)$ & \\
\hline FLT3-ITD, No. (\%) & & & .59 \\
\hline Mutated & $26(25.5)$ & $22(22.2)$ & \\
\hline Unmutated & 76 (74.5) & 77 (77.8) & \\
\hline Missing & $27(21)$ & $38(28)$ & \\
\hline
\end{tabular}

Abbreviations: ATO, arsenic trioxide; ATRA, all-trans-retinoic acid; CHT, che motherapy; ITD, internal tandem duplication.

Leukocytosis greater than $10 \times 10^{9} / \mathrm{L}$ developed during induction in 56 patients (43\%) receiving ATRA-ATO and was successfully managed in all patients with hydroxyurea as per protocol recommendation. Moderate and severe DS (defined as in Montesinos et $\mathrm{al}^{24}$ ) occurred during induction in 16 patients (13\%) and five patients $(4 \%)$ in the ATRA-ATO arm and in nine patients $(7 \%)$ and eight patients $(6 \%)$ in the ATRA-CHT arm, respectively $(P=.38)$, and was fatal in two patients in the ATRA-CHT arm. In eight patients (four patients in each arm), indeterminate DS (defined according to Frankel et $\mathrm{al}^{25}$ ) was reported.

\section{Consolidation Therapy}

Of 259 patients who proceeded to consolidation therapy, 234 patients (115 in the ATRA-ATO arm and 119 in the ATRA-CHT arm) were evaluable for molecular response after the third consolidation cycle. Twelve of 127 patients in the ATRA-ATO arm went off protocol before the bone marrow assessment after third consolidation as a result of major protocol violation $(\mathrm{n}=2)$, consent withdrawal $(\mathrm{n}=1)$, medical decision $(\mathrm{n}=1)$, loss to follow-up $(n=2)$, toxicity $(n=4)$, or missing data $(n=2)$. In the
ATRA-CHT arm, 13 of 132 patients did not undergo bone marrow evaluation after third consolidation because of major protocol violation (PCR not performed, $\mathrm{n}=1)$, loss to follow-up $(\mathrm{n}=4)$, toxicity $(n=6)$, hepatitis reactivation $(n=1)$, or missing data $(n=1)$. Six patients (one in the ATRA-ATO arm and five in the ATRA-CHT arm) died in CR. The patient in the ATRA-ATO group died of bronchopneumonia driven by $\mathrm{H} 1 \mathrm{~N} 1$ virus. Of the five deaths in the ATRA-CHT group, one was caused by hemorrhagic shock, one by pulmonary embolism, two by bronchopneumonia, and one by secondary myelodysplastic syndrome.

Molecular evaluation of PML-RARA by RT-PCR after third consolidation showed PCR negativity in all patients in the ATRAATO arm, whereas two (1.7\%) of 119 patients in the ATRA-CHT arm tested positive by PCR and were considered as having molecular resistance. Of these, one patient was treated with ATO salvage therapy followed by allogeneic stem-cell transplantation and remained in second CR 14 months after transplantation. In the other patient, a second PCR test after the end of consolidation did not confirm PCR positivity. The patient was continued on ATRA and low-dose CHT maintenance and remained in remission for greater than 24 months.

\section{Maintenance Therapy (ATRA-CHT Arm)}

All 117 patients in the ATRA-CHT arm who completed consolidation and tested RT-PCR negative for PML-RARA proceeded to maintenance. Excluding the nine patients who experienced relapse during maintenance, 20 patients did not complete maintenance as a result of toxicity $(n=4)$, treatment refusal $(n=3)$, major protocol violation $(n=1)$, or other reasons $(n=12)$.

\section{Toxicities}

Hematologic and nonhematologic toxicities are listed in Tables 2 and 3, respectively. A total of 95 serious adverse events (SAEs) were reported in 65 patients. Of these, 43 and 52 SAEs were reported in patients receiving ATRA-ATO and ATRA-CHT, respectively. The complete list of detailed SAEs is reported in Appendix Table A1 (online only).

Hematologic toxicity. As shown in Table 2, a significantly higher number of patients in the ATRA-CHT arm compared with the ATRA-ATO arm experienced grade 3 or 4 neutropenia and thrombocytopenia lasting more than 15 days $(P<.001)$. Episodes of febrile neutropenia (including fever of unknown origin and

\begin{tabular}{|c|c|c|c|c|c|c|c|c|}
\hline \multirow[b]{2}{*}{ Toxicity and Treatment Arm } & \multicolumn{2}{|c|}{ Induction } & \multicolumn{2}{|c|}{ First Consolidation } & \multicolumn{2}{|c|}{ Second Consolidation } & \multicolumn{2}{|c|}{ Third Consolidation } \\
\hline & No. (\%) & $P$ & No. (\%) & $P$ & No. (\%) & $P$ & No. (\%) & $P$ \\
\hline Neutropenia (grade 3-4 lasting $>15$ days) & & $<.001$ & & $<.001$ & & $<.001$ & & $<.001$ \\
\hline ATRA-ATO & $61(35)$ & & 8 (16) & & $7(7)$ & & $5(15)$ & \\
\hline ATRA-CHT & $109(64)$ & & $40(67)$ & & $90(92)$ & & $28(85)$ & \\
\hline Thrombocytopenia (grade $3-4$ lasting $>15$ days) & & $<.001$ & & $<.001$ & & $<.001$ & & $<.001$ \\
\hline ATRA-ATO & $74(38)$ & & $6(26)$ & & $6(7)$ & & $8(23)$ & \\
\hline ATRA-CHT & $120(62)$ & & $17(74)$ & & 77 (93) & & $26(76)$ & \\
\hline Infection and FUO & & $<.001$ & & .54 & & $<.001$ & & 1.0 \\
\hline ATRA-ATO & $30(23)$ & & $10(8)$ & & $4(3)$ & & $2(1.6)$ & \\
\hline ATRA-CHT & $75(55)$ & & $8(6)$ & & $46(38)$ & & $2(1.7)$ & \\
\hline
\end{tabular}

Abbreviations: ATO, arsenic trioxide; ATRA, all-trans-retinoic acid; CHT, chemotherapy; FUO, fever of unknown origin. 


\begin{tabular}{|c|c|c|c|c|c|c|c|c|}
\hline \multirow[b]{2}{*}{ Toxicity and Treatment Arm } & \multicolumn{2}{|c|}{ Induction } & \multicolumn{2}{|c|}{ First Consolidation } & \multicolumn{2}{|c|}{ Second Consolidation } & \multicolumn{2}{|c|}{ Third Consolidation } \\
\hline & No. $(\%)$ & $P$ & No. $(\%)$ & $P$ & No. $(\%)$ & $P$ & No. $(\%)$ & $P$ \\
\hline Hepatic toxicity (grade $3-4$ ) & & $<.001$ & & .11 & & .49 & & \\
\hline ATRA-ATO & $51(40)$ & & $5(4)$ & & $1(0.8)$ & & 0 & \\
\hline ATRA-CHT & $4(3)$ & & $1(0.7)$ & & 0 & & 0 & \\
\hline QTc prolongation & & .0022 & & .11 & & .11 & & .23 \\
\hline ATRA-ATO & $11(8.5)$ & & $3(2)$ & & $3(2)$ & & $2(1.5)$ & \\
\hline ATRA-CHT & $1(0.7)$ & & 0 & & 0 & & 0 & \\
\hline Cardiac function (grade 3-4) & & .06 & & & & & & \\
\hline ATRA-ATO & 0 & & 0 & & 0 & & 0 & \\
\hline ATRA-CHT & $5(3.7)$ & & 0 & & 0 & & 0 & \\
\hline Neurotoxicity (all grades) & & .48 & & .02 & & .01 & & .006 \\
\hline ATRA-ATO & $1(0.7)$ & & $5(4.2)$ & & $6(5)$ & & 7 (5.9) & \\
\hline ATRA-CHT & 0 & & 0 & & 0 & & 0 & \\
\hline GI toxicity (grade 3-4) & & $<.001$ & & 1.0 & & .03 & & 1.0 \\
\hline ATRA-ATO & $3(2)$ & & 0 & & 0 & & 0 & \\
\hline ATRA-CHT & 25 (18.2) & & $1(0.8)$ & & $6(4.9)$ & & 0 & \\
\hline Hypercholesterolemia & & .55 & & .13 & & .14 & & .27 \\
\hline ATRA-ATO & $14(10)$ & & $19(16)$ & & $19(16)$ & & $16(14)$ & \\
\hline ATRA-CHT & $12(8.7)$ & & $12(9.6)$ & & $12(9.7)$ & & $11(9)$ & \\
\hline Hypertriglyceridemia & & 0.76 & & .49 & & .12 & & .5 \\
\hline ATRA-ATO & $29(22)$ & & 22 (18.4) & & 17 (14.4) & & $16(14)$ & \\
\hline ATRA-CHT & $29(22)$ & & 19 (15.2) & & $10(8)$ & & $13(11)$ & \\
\hline
\end{tabular}

documented infections counted together) were also significantly more frequent in the ATRA-CHT arm than in the ATRA-ATO arm. In particular, in the ATRA-ATO and ATRA-CHT arms, 30 and 75 episodes were documented during the induction course $(P<.001)$, 10 and eight occurred during the first consolidation cycle $(P=.54)$, four and 46 occurred during the second consolidation cycle $(P<.001)$, and two and two occurred during the third consolidation cycle $(P=1.0)$, respectively.

Other toxicities. Significant elevation of liver function tests (grade 3 or 4 according to National Cancer Institute Common Terminology Criteria for Adverse Events) was more frequent in the ATRA-ATO arm (44\%) compared with the ATRA-CHT (3\%) arm across all treatment cycles $(P<.001)$. Toxicity resolved in all patients with temporary discontinuation of ATO and/or ATRA or of low-dose CHT during maintenance (for patients in the ATRACHT arm). QTc prolongation, defined as QTc greater than 450 milliseconds for men and greater than 460 milliseconds for women with correction calculated using the Framingham formula, was observed in 15 patients $(11 \%)$ in the ATRA-ATO arm and one patient in the ATRA-CHT arm $(P<.001)$ throughout the treatment cycles. There were no cases of life-threatening cardiac arrhythmias; however, ATO was permanently discontinued in one of the 15 patients, and the patient went off protocol. Neurotoxicity mainly consisting of reversible peripheral nerve neuropathy was observed in a greater proportion of patients in the ATRA-ATO arm and occurred during consolidation. Finally, GI toxicity and cardiac function abnormalities were significantly more frequent in the ATRA-CHT arm (Table 3).

\section{Outcomes}

All outcome estimates calculated at 24 and 50 months are listed in Table 4, whereas outcome curves are shown in Figure 2.
Primary end point. A total of 263 patients (127 and 136 in the ATRA-ATO and ATRA-CHT arms, respectively) were evaluable for EFS according to the intent-to-treat analysis. In the ATRA-ATO group, 98.3\% of patients (95\% CI, 95.9\% to $100 \%$ ) were event free at 24 months from random assignment, compared with $86.8 \%$ in the ATRA-CHT group (95\% CI, $81.1 \%$ to $92.8 \%$; $P<.001$ ). At 50 months, EFS estimates were $97.3 \%$ (95\% CI, $94.3 \%$ to $100 \%$ ) and $80.0 \%$ (95\% CI, $72.9 \%$ to $88.0 \%$ ) in the ATRA-ATO and ATRA-CHT groups, respectively. Although 263 patients is not the full intent-to-treat complement for EFS evaluation, the number of unevaluable patients was small.

The noninferiority analysis was carried out in 229 patients with sufficient follow-up (beyond 24 months). Of these patients,

\begin{tabular}{|c|c|c|c|}
\hline \multirow{2}{*}{$\begin{array}{l}\text { Outcome and } \\
\text { Treatment Arm }\end{array}$} & \multicolumn{2}{|c|}{ Probability, \% (95\% Cl) } & \multirow[b]{2}{*}{$P$} \\
\hline & 24 Months & 50 Months & \\
\hline \multicolumn{3}{|l|}{ Overall survival } & \multirow[t]{3}{*}{.0073} \\
\hline ATRA-ATO & 99.2 (97.7 to 100$)$ & 99.2 (97.7 to 100$)$ & \\
\hline ATRA-CHT & 94.8 (91.1 to 98.6 ) & 92.6 (87.9 to 97.5$)$ & \\
\hline \multicolumn{3}{|l|}{ Event-free survival } & \multirow[t]{3}{*}{$<.001$} \\
\hline ATRA-ATO & 98.3 (95.9 to 100$)$ & 97.3 (94.3 to 100$)$ & \\
\hline ATRA-CHT & 86.8 (81.1 to 92.8 ) & 80.0 (72.9 to 88.0$)$ & \\
\hline \multicolumn{3}{|l|}{$\begin{array}{c}\text { Disease-free } \\
\text { survival }\end{array}$} & \multirow[t]{3}{*}{$<.001$} \\
\hline ATRA-ATO & 98.3 (95.9 to 100$)$ & $97.3(94.3$ to 100$)$ & \\
\hline ATRA-CHT & $89.4(84.1$ to 95.0$)$ & 82.6 (75.6 to 90.3$)$ & \\
\hline \multicolumn{3}{|l|}{$\begin{array}{l}\text { Cumulative incidence } \\
\text { of relapse }\end{array}$} & \multirow[t]{3}{*}{$.0013^{*}$} \\
\hline ATRA-ATO & $0.9(0$ to 2.7$)$ & $1.9(0.0$ to 4.5$)$ & \\
\hline ATRA-CHT & 8.2 (3.3 to 13.2$)$ & 13.9 (7.1 to 20.6$)$ & \\
\hline \multicolumn{4}{|c|}{$\begin{array}{l}\text { Abbreviations: ATO, arsenic trioxide; ATRA, all-trans-retinoic acid; CHT, } \\
\text { chemotherapy. } \\
{ }^{*} \text { Gray test. }\end{array}$} \\
\hline
\end{tabular}


98.15\% in the ATRA-ATO group (106 of 108 patients) were alive and event free at 24 months, compared with $85.95 \%$ of patients in the ATRA-CHT group (104 of 121 patients), with a difference in the EFS rates at 2 years of $12.2 \%$ (95\% CI, $4.3 \%$ to $20.1 \%$ ); because the lower bound of the $95 \%$ CI for this difference was $\geq 5 \%$, the noninferiority of ATRA-ATO was confirmed $(P<.001)$.

Seventeen patients experienced relapse during follow-up. Of these, two relapses occurred in the ATRA-ATO arm at 22 and 27 months, and 15 occurred in the ATRA-CHT arm at a median time of 14.0 months (range, 2.5 to 39.8 months). In four patients, relapse was detected at the molecular level before hematologic relapse, leading to administration of pre-emptive salvage therapy. Two patients in the ATRA-CHT arm and none in the ATRA-ATO arm developed a therapy-related myeloid neoplasm. Of these, one patient with therapy-related myelodysplastic syndrome died as a result of disease progression, whereas in the other patient, a therapy-related acute myeloid leukemia was diagnosed, and the patient remained alive in CR 14 months after undergoing allogeneic stem-cell transplantation.

Secondary end points. The 24- and 50-month OS, DFS, and CIR rates for patients in the two arms are listed in Table 4. The results of the kinetics of molecular response and impact of FLT3 status will be reported in a separate publication.

Regarding QoL, the results of the current extended series broadly confirm previously reported findings ${ }^{26}$ on the benefits of ATRA-ATO versus ATRA-CHT after induction therapy. The previous main observation that fatigue severity (as measured by the European Organisation for Research and Treatment of Cancer Quality of Life Questionnaire C30) was significantly lower in the group treated with ATRA-ATO versus ATRA-CHT after induction therapy $(P=.034)^{26}$ was fully confirmed in this larger patient population $(P=.008)$. A long-term QoL analysis has been planned, and full details will be reported separately.

\section{DISCUSSION}

This study shows that, compared with ATRA-CHT, the ATRA-ATO combination significantly improved both survival and relapse risk in patients with newly diagnosed, low- or intermediate-risk APL. Compared with our previous report in which no significant differences in DFS and CIR rates were found, we report here that the

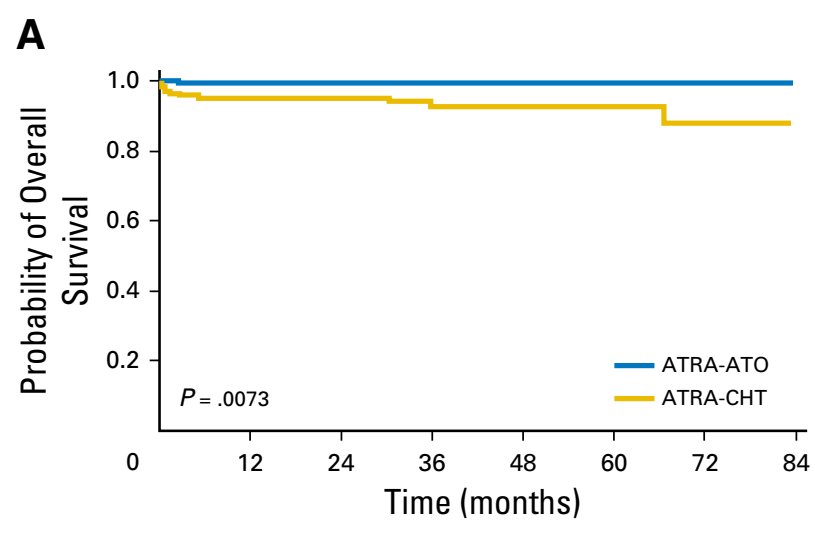

B

$\begin{array}{llllllll}\text { ATRA-ATO } & 129 & 118 & 107 & 84 & 58 & 32 & 8 \\ \text { ATRA-CHT } & 137 & 116 & 111 & 74 & 44 & 33 & 7\end{array}$

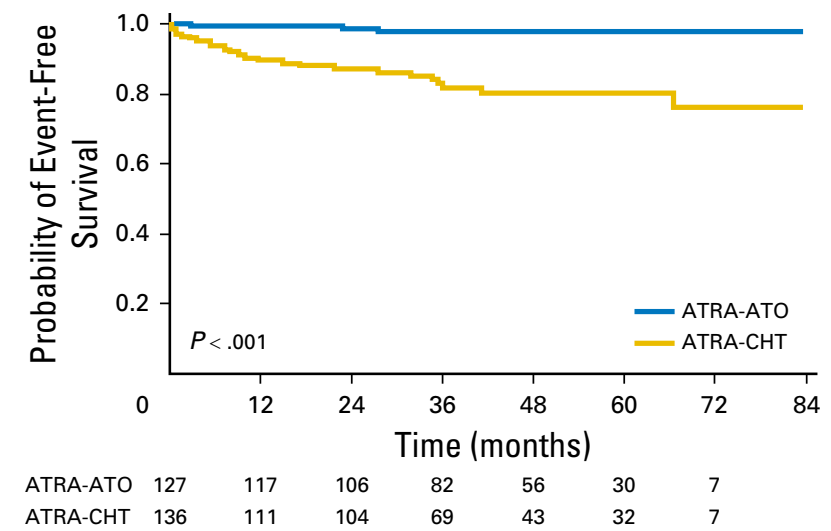

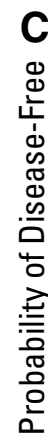

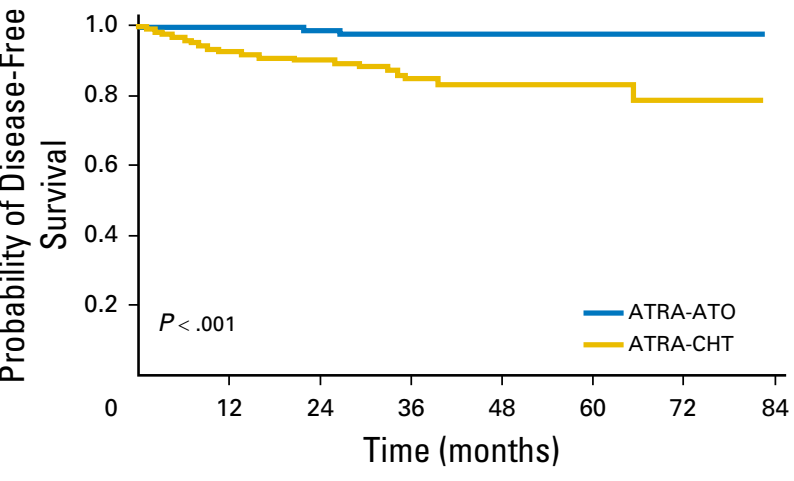

$\begin{array}{llllllll}\text { ATRA-ATO } & 127 & 116 & 105 & 77 & 51 & 25 & 5\end{array}$

$\begin{array}{llllllll}\text { ATRA-CHT } & 132 & 111 & 103 & 66 & 40 & 31 & 6\end{array}$

D

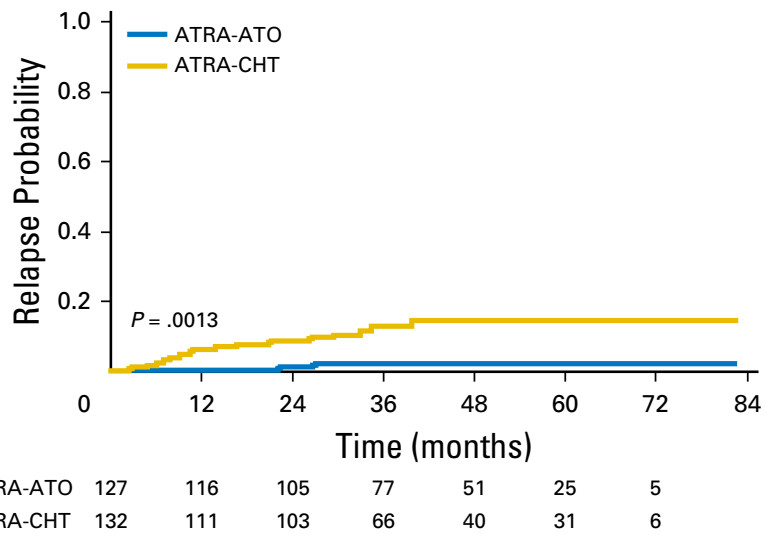

Fig 2. Outcome estimates. (A) Overall survival. (B) Event-free survival. (C) Disease-free survival. (D) Relapse. ATO, arsenic trioxide; ATRA, all-trans-retinoic acid; $\mathrm{CHT}$, chemotherapy. 
CHT-free approach based on ATRA-ATO resulted in higher antileukemic efficacy. In addition, the present analysis conducted in a substantially extended cohort of patients with prolonged followup revealed significantly improved differences in all other analyzed outcomes (EFS, OS, and DFS) compared with the initial report. ${ }^{20}$ These data indicate that the advantage of ATRA-ATO over ATRACHT increases over time and that the inclusion of ATO in the treatment of low- or intermediate-risk APL not only reduces mortality and hematologic toxicity, but also results in improved and sustained antileukemic activity. Neither additional fatal events nor further relapses were recorded in patients randomly assigned to ATRA-ATO in this extended cohort. By contrast, new relapses, two instances of molecular resistance (ie, testing PCR positive after third consolidation), and two therapy-related myeloid neoplasms were observed in the group of patients receiving ATRA-CHT.

A recent study conducted in the United Kingdom by the National Cancer Research Institute (NCRI) reported similar results in terms of EFS and relapse rate, with patients treated with ATRA-ATO showing significantly better outcomes. ${ }^{21}$ At variance from our study, the NCRI trial used an ATO schedule consisting of two or three weekly administrations at increased doses and included no maintenance in the ATRA-CHT arm (which was otherwise derived from the same ATRA and idarubicin [AIDA] protocol used in our study). Furthermore, the study included patients with high-risk disease, for whom a provision was made to use one or two $6 \mathrm{mg} / \mathrm{m}^{2}$ doses of gemtuzumab ozogamicin during the first 4 days of induction. This important study independently confirmed the advantage of including ATO in first-line management of APL, suggesting that the benefit is also observed in high-risk patients. In this respect, however, it should be noted that a total of 57 patients with high-risk disease were included in the comparison and that the efficacy of ATO in this patient subset may be difficult to analyze given the addition of a potent anti-APL agent such as gemtuzumab ozogamicin. ${ }^{21} \mathrm{~A}$ randomized trial comparing ATRA-ATO to the AIDA2000 protocol $^{5}$ and involving several European cooperative groups will be started soon to further investigate this issue.

The toxicity profiles in the current study were comparable to those observed for the two cohorts in the original series. For patients receiving ATRA-ATO, adverse effects mainly consisted of frequent increase of liver enzymes, QTc prolongation, and hyperleukocytosis. In almost all patients, this toxicity was reversible and manageable with temporary drug interruption and dose adjustments as per protocol recommendations, including the addition of hydroxyurea (the only cytotoxic agent allowed for the control of hyperleukocytosis). The study from the United King$\mathrm{dom}^{21}$ reported similar toxicities for patients in the ATO group in terms of DS and cardiac adverse effects, but a lower incidence of grade 3 or 4 hepatic toxicity, probably as a result of the different schedule. Regarding medium- and long-term toxicity, the absence of secondary therapy-related myeloid neoplasms at the extended follow-up in the ATRA-ATO cohort also represents a major improvement in the treatment of a disease where high cure rates are achieved.

In conclusion, in line with results of pilot studies ${ }^{18,19}$ and those of the recent randomized NCRI trial, ${ }^{21}$ our results support the use of ATRA-ATO in patients with newly diagnosed APL and point to this strategy as the new standard of care for low- or intermediate-risk patients. Studies exploring the role of ATRAATO are warranted in other APL subsets including high-risk, pediatric, and elderly patients.

\section{AUTHORS' DISCLOSURES OF POTENTIAL CONFLICTS} OF INTEREST

Disclosures provided by the authors are available with this article at www.jco.org.

\section{AUTHOR CONTRIBUTIONS}

Conception and design: Uwe Platzbecker, Giuseppe Avvisati, Marco Vignetti, Felicetto Ferrara, Eros Di Bona, Massimo Breccia, Francesco Fabbiano, Franco Mandelli, Gerhard Ehninger, Francesco Lo-Coco Administrative support: Helmut R. Salih, Mohammed Wattad Provision of study materials or patients: Felicetto Ferrara, Francesco Albano, Marco Sborgia, Eros Di Bona, Massimo Breccia, Erika Borlenghi, Roberto Cairoli, Alessandro Rambaldi, Lorella Melillo, Giorgio La Nasa, Walter Fiedler, Peter Brossart, Bernd Hertenstein, Michael Lübbert, Christian H. Brandts, Mathias Hänel, Christoph Röllig, Norbert Schmitz, Hartmut Link, Chiara Frairia, Enrico Maria Pogliani, Claudio Fozza, Alfonso Maria D’Arco, Nicola Di Renzo, Agostino Cortelezzi, Arnold Ganser, Hartmut Döhner, Sergio Amadori, Richard F. Schlenk

Collection and assembly of data: Uwe Platzbecker, Christian Thiede, Marco Vignetti, Mariadomenica Divona, Francesco Albano, Paola Fazi, Marco Sborgia, Erika Borlenghi, Roberto Cairoli, Alessandro Rambaldi, Lorella Melillo, Giorgio La Nasa, Walter Fiedler, Peter Brossart, Bernd Hertenstein, Helmut R. Salih, Mohammed Wattad, Michael Lübbert, Christian H. Brandts, Mathias Hänel, Christoph Röllig, Norbert Schmitz, Hartmut Link, Chiara Frairia, Enrico Maria Pogliani, Claudio Fozza, Alfonso Maria D’Arco, Nicola Di Renzo, Agostino Cortelezzi, Konstanze Döhner, Arnold Ganser, Sergio Amadori, Gerhard Ehninger

Data analysis and interpretation: Uwe Platzbecker, Laura Cicconi, Francesca Paoloni, Marco Vignetti, Fabio Efficace, Hartmut Döhner, Gerhard Ehninger, Richard F. Schlenk

Manuscript writing: All authors

Final approval of manuscript: All authors

\section{REFERENCES}

1. Tallman MS, Andersen JW, Schiffer CA, et al: All-trans retinoic acid in acute promyelocytic leukemia: Long-term outcome and prognostic factor analysis from the North American Intergroup protocol. Blood 100:4298-4302, 2002

2. Asou N, Kishimoto $Y$, Kiyoi $H$, et al: A randomized study with or without intensified maintenance chemotherapy in patients with acute promyelocytic leukemia who have become negative for PMLRARalpha transcript after consolidation therapy: The Japan Adult Leukemia Study Group (JALSG) APL97 study. Blood 110:59-66, 2007

3. Lengfelder E, Haferlach $C$, Saussele $S$, et al: High dose ara-C in the treatment of newly diagnosed acute promyelocytic leukemia: Long-term results of the German AMLCG. Leukemia 23:2248-2258, 2009

4. Adès L, Guerci A, Raffoux E, et al: Very longterm outcome of acute promyelocytic leukemia after treatment with all-trans retinoic acid and chemotherapy:
The European APL Group experience. Blood 115 1690-1696, 2010

5. Sanz MA, Montesinos $P$, Rayón $C$, et al: Risk-adapted treatment of acute promyelocytic leukemia based on all-trans retinoic acid and anthracycline with addition of cytarabine in consolidation therapy for high-risk patients: Further improvements in treatment outcome. Blood 115: 5137-5146, 2010

6. Avvisati G, Lo-Coco F, Paoloni FP, et al: AIDA 0493 protocol for newly diagnosed acute promyelocytic 
leukemia: Very long-term results and role of maintenance. Blood 117:4716-4725, 2011

7. Iland $H$, Bradstock $K$, Seymour J, et al: Results of the APML3 trial incorporating all-transretinoic acid and idarubicin in both induction and consolidation as initial therapy for patients with acute promyelocytic leukemia. Haematologica 97: 227-234, 2012

8. Burnett AK, Hills RK, Grimwade D, et al: Inclusion of chemotherapy in addition to anthracycline in the treatment of acute promyelocytic leukaemia does not improve outcomes: Results of the MRC AML15 trial. Leukemia 27:843-851, 2013

9. Sanz MA, Grimwade D, Tallman MS, et al: Management of acute promyelocytic leukemia: Recommendations from an expert panel on behalf of the European LeukemiaNet. Blood 113:1875-1891, 2009

10. Wang ZY, Chen Z: Acute promyelocytic leukemia: From highly fatal to highly curable. Blood 111 : 2505-2515, 2008

11. Montesinos P, González JD, González J, et al: Therapy-related myeloid neoplasms in patients with acute promyelocytic leukemia treated with all-transretinoic acid and anthracycline-based chemotherapy. J Clin Oncol 28:3872-3879, 2010

12. de Thé $H$, Le Bras $M$, Lallemand-Breitenbach $\mathrm{V}$ : The cell biology of disease: Acute promyelocytic leukemia, arsenic, and PML bodies. J Cell Biol 198: 11-21, 2012
13. Mathews V, Chendamarai E, George B, et al: Treatment of acute promyelocytic leukemia with single-agent arsenic trioxide. Mediterr J Hematol Infect Dis 3:e2011056, 2011

14. Breccia M, Lo-Coco F: Arsenic trioxide for management of acute promyelocytic leukemia: Current evidence on its role in front-line therapy and recurrent disease. Expert Opin Pharmacother 13: 1031-1043, 2012

15. Shao W, Fanelli M, Ferrara FF, et al: Arsenic trioxide as an inducer of apoptosis and loss of PML/ RAR alpha protein in acute promyelocytic leukemia cells. J Natl Cancer Inst 90:124-133, 1998

16. Ghavamzadeh $A$, Alimoghaddam $K$, Rostami $\mathrm{S}$, et al: Phase II study of single-agent arsenic trioxide for the front-line therapy of acute promyelocytic leukemia. J Clin Oncol 29:2753-2757, 2011

17. Mathews V, George B, Lakshmi KM, et al: Single-agent arsenic trioxide in the treatment of newly diagnosed acute promyelocytic leukemia: Durable remissions with minimal toxicity. Blood 107: 2627-2632, 2006

18. Estey E, Garcia-Manero G, Ferrajoli A, et al: Use of all-trans retinoic acid plus arsenic trioxide as an alternative to chemotherapy in untreated acute promyelocytic leukemia. Blood 107:3469-3473, 2006

19. Ravandi F, Estey E, Jones D, et al: Effective treatment of acute promyelocytic leukemia with alltrans-retinoic acid, arsenic trioxide, and gemtuzumab ozogamicin. J Clin Oncol 27:504-510, 2009
20. Lo-Coco F, Avvisati G, Vignetti M, et al: Retinoic acid and arsenic trioxide for acute promyelocytic leukemia. N Engl J Med 369:111-121, 2013

21. Burnett $A K$, Russell NH, Hills RK, et al: Arsenic trioxide and all-trans retinoic acid treatment for acute promyelocytic leukaemia in all risk groups (AML17): Results of a randomised, controlled, phase 3 trial. Lancet Oncol 16:1295-1305, 2015

22. National Comprehensive Cancer Network: NCCN Guidelines: Acute Myeloid Leukemia. Version 1.2015. www.nccn.org

23. Seftel MD, Barnett MJ, Couban $S$, et al.: A Canadian consensus on the management of newly diagnosed and relapsed acute promyelocytic leukemia in adults. Curr Oncol 21:234-250, 2014

24. Montesinos $P$, Bergua JM, Vellenga $E$, et al: Differentiation syndrome in patients with acute promyelocytic leukemia treated with all-trans retinoic acid and anthracycline chemotherapy: Characteristics, outcome, and prognostic factors. Blood 113: 775-783, 2009

25. Frankel SR, Eardley A, Lauwers G, et al: The "retinoic acid syndrome" in acute promyelocytic leukemia. Ann Intern Med 117:292-296, 1992

26. Efficace F, Mandelli F, Avvisati G, et al: Randomized phase III trial of retinoic acid and arsenic trioxide versus retinoic acid and chemotherapy in patients with acute promyelocytic leukemia: Healthrelated quality-of-life outcomes. J Clin Oncol 32: 3406-3412, 2014

\section{Affiliations}

Uwe Platzbecker, Christian Thiede, Christoph Röllig, and Gerhard Ehninger, Universitätsklinikum Carl Gustav Carus der Technischen Universität Dresden; Uwe Platzbecker and Gerhard Ehninger, Study Alliance Leukemia, Dresden; Walter Fiedler, University Hospital Hamburg-Eppendorf; Norbert Schmitz, Asklepios Klinik St Georg Hamburg, Hamburg; Peter Brossart, Innere Medizin mit deSchwerpunkten Onkologie, Haematollogie un Rheumatologie, Bonn; Bernd Hertenstein, Klinikum Bremen Mitte, Bremen; Helmut R. Salih, University Hospital Tubingen; Mohammed Wattad, Kliniken Essen Süd, Essen; Michael Lübbert, University Medical Center, Freiburg; Christian H. Brandts, Goethe University Frankfurt, Frankfurt; Mathias Hänel, Klinikum Chemnitz gGmbH, Chemnitz; Hartmut Link, Klinik für Innere Medizin I, Westpfalz-Klinikum, Kaiserslautern; Konstanze Döhner, Hartmut Döhner, and Richard F. Schlenk, University Hospital Ulm, Ulm; Arnold Ganser, Hannover Medical School, Hannover, Germany; Giuseppe Avvisati, University Campus Bio-Medico; Laura Cicconi, Mariadomenica Divona, Sergio Amadori, and Francesco Lo-Coco, University Tor Vergata; Francesca Paoloni, Marco Vignetti, Fabio Efficace, Paola Fazi, and Franco Mandelli, Gruppo Italiano Malattie Ematologiche dell'Adulto Central Office; Marco Vignetti and Massimo Breccia, Sapienza University, Rome; Felicetto Ferrara, Cardarelli Hospital, Naples; Francesco Albano, University of Bari, Bari; Marco Sborgia, U.O. di Ematologia Clinica, Pescara; Eros Di Bona, San Bortolo Hospital, Vicenza; Erika Borlenghi, U.O. di Ematologia, Spedali Civili, Brescia; Roberto Cairoli, Ospedale Niguarda, Ca' Granda, SC Ematologia; Agostino Cortelezzi, Foundation Istituto di Ricovero e Cura a Carattere Scientifico Ca' Granda Ospedale Maggiore Policlinico and University of Milan, Milano; Alessandro Rambaldi, Azienda Opsedaliera Papa Giovanni XXIII, Bergamo; Lorella Melillo, Casa Sollievo della Sofferenza Hospital, IRCCS, San Giovanni Rotondo; Giorgio La Nasa, Centro Trapianti Midollo Osseo, Ospedale R. Binaghi, Università di Cagliari, Cagliari; Chiara Frairia, Hematology, Città della Salute e della Scienza, Torino; Enrico Maria Pogliani, Ospedale San Gerardo, Università degli Studi Milano Bicocca, Monza; Claudio Fozza, University of Sassari, Sassari; Alfonso Maria D’Arco, U.O. Medicina Interna e OncoEmatologica P.O. “Umberto I," Nocera Inferiore, Nocera Inferiore; Nicola Di Renzo, Ospedale Vito Fazzi, Lecce; and Francesco Fabbiano, Ospedali Riuniti Villa Sofia-Cervello, Palermo, Italy. 


\section{AUTHORS' DISCLOSURES OF POTENTIAL CONFLICTS OF INTEREST}

Improved Outcomes With Retinoic Acid and Arsenic Trioxide Compared With Retinoic Acid and Chemotherapy in Non-High-Risk Acute Promyelocytic Leukemia: Final Results of the Randomized Italian-German APL0406 Trial

The following represents disclosure information provided by authors of this manuscript. All relationships are considered compensated. Relationships are self-held unless noted. I = Immediate Family Member, Inst = My Institution. Relationships may not relate to the subject matter of this manuscript. For more information about ASCO's conflict of interest policy, please refer to www.asco.org/rwc or jco.ascopubs.org/site/ifc.

Uwe Platzbecker

Honoraria: Celgene, Amgen, Novartis, Janssen-Cilag, Teva Pharmaceutical Industries

Research Funding: Teva Pharmaceutical Industries (Inst), Novartis (Inst), Celgene (Inst), Janssen-Cilag (Inst), Amgen (Inst)

Giuseppe Avvisati

No relationship to disclose

\section{Laura Cicconi}

Speakers' Bureau: Teva Pharmaceutical Industries

Christian Thiede

Employment: AgenDix

Leadership: AgenDix

Stock or Other Ownership: AgenDix

Honoraria: Novartis, AstraZeneca

Consulting or Advisory Role: AstraZeneca

Research Funding: Bayer

Francesca Paoloni

No relationship to disclose

Marco Vignetti

No relationship to disclose

\section{Felicetto Ferrara}

No relationship to disclose

\section{Mariadomenica Divona}

No relationship to disclose

Francesco Albano

No relationship to disclose

Fabio Efficace

Consulting or Advisory Role: Bristol-Myers Squibb, Seattle Genetics, Teva Pharmaceutical Industries

Research Funding: Bristol-Myers Squibb (Inst), Lundbeck (Inst)

Paola Fazi

No relationship to disclose

Marco Sborgia

No relationship to disclose

Eros Di Bona

No relationship to disclose

Massimo Breccia

Honoraria: Novartis, Bristol-Myers Squibb, Pfizer, Ariad Pharmaceuticals Consulting or Advisory Role: Novartis

Erika Borlenghi

No relationship to disclose

Roberto Cairoli

No relationship to disclose

Alessandro Rambaldi

No relationship to disclose

Lorella Melillo

Travel, Accommodations, Expenses: Roche

\section{Giorgio La Nasa}

Consulting or Advisory Role: Bristol-Myers Squibb, Amgen

\section{Walter Fiedler}

Consulting or Advisory Role: Amgen

Research Funding: Pfizer Pharma (Inst), Amgen (Inst)

Patents, Royalties, Other Intellectual Property: Amgen

Travel, Accommodations, Expenses: Teva Pharmaceutical Industries, Gilead Sciences, Amgen, Gesellschaft Studienmanagement Onkologie

Peter Brossart

No relationship to disclose

\section{Bernd Hertenstein}

Travel, Accommodations, Expenses: Novartis, Amgen, Teva

Pharmaceutical Industries, Neovii Biotech

Helmut R. Salih

Consulting or Advisory Role: Novartis

Mohammed Wattad

No relationship to disclose

Michael Lübbert

Consulting or Advisory Role: Janssen-Cilag

Christian H. Brandts

No relationship to disclose

Mathias Hänel

No relationship to disclose

Christoph Röllig

Honoraria: Amgen, Roche, Celgene, Novartis, Bristol-Myers Squibb, Janssen, Takeda

\section{Norbert Schmitz}

Honoraria: Roche, Celgene, Riemser Pharma, Cell Technology Inc Consulting or Advisory Role: Roche, Celgene, Riemser Pharma, Cell Technology Inc

Research Funding: Roche, Celgene

Travel, Accommodations, Expenses: Roche, Celgene, Riemser Pharma, Cell Technology Inc

\section{Hartmut Link}

Honoraria: Amgen, Teva Pharmaceutical Industries, Novartis, Pfizer, Celgene

Consulting or Advisory Role: Amgen, Novartis, Teva Pharmaceutical Industries, Merck Sharp \& Dohme Oncology, Celgene, Vifor Pharma, Eli Lilly, Mundipharma

Speakers' Bureau: Amgen, Teva Pharmaceutical Industries, Vifor Pharma, Merck Sharp \& Dohme Oncology

Research Funding: Amgen, Merck Sharp \& Dohme Oncology, Hexal, Teva Pharmaceutical Industries

\section{Chiara Frairia}

No relationship to disclose

Enrico Maria Pogliani

No relationship to disclose

Claudio Fozza

No relationship to disclose 
Alfonso Maria D'Arco

No relationship to disclose

\section{Nicola Di Renzo}

No relationship to disclose

Agostino Cortelezzi

No relationship to disclose

Francesco Fabbiano

Consulting or Advisory Role: Amgen, Ariad Pharmaceuticals

Konstanze Döhner

No relationship to disclose

Arnold Ganser

Honoraria: Celgene, Boehringer Ingelheim, Novartis

Consulting or Advisory Role: Celgene

Hartmut Döhner

Consulting or Advisory Role: Agios, Astex Pharmaceuticals, Celator, Celgene, GlaxoSmithKline, Novartis, Roche, Seattle Genetics, Sunesis Pharmaceuticals, Tolero Pharmaceuticals

Travel, Accommodations, Expenses: Amgen, Celgene

Sergio Amadori

No relationship to disclose
Franco Mandelli

No relationship to disclose

Gerhard Ehninger

Leadership: Rhoen-Klinikum AG

Stock or Other Ownership: Celgene, Gilead Sciences, Fresenius Medical Care

Honoraria: Novartis

Patents, Royalties, Other Intellectual Property: GEMoaB Monoclonals Travel, Accommodations, Expenses: Novartis

Richard F. Schlenk

Honoraria: Janssen, Novartis, Celgene, Teva Pharmaceutical Industries, Pfizer

Consulting or Advisory Role: Daiichi Sankyo

Research Funding: Novartis (Inst), Celgene (Inst), Amgen (Inst), Teva Pharmaceutical Industries (Inst), Pfizer (Inst)

Francesco Lo-Coco

Honoraria: Teva Pharmaceutical Industries, Lundbeck

Consulting or Advisory Role: Teva Pharmaceutical Industries, Novartis, Baxalta, Pfizer

Speakers' Bureau: Teva Pharmaceutical Industries, Lundbeck 


\section{Acknowledgment}

We thank Giorgio Minotti, MD, and Maria Teresa Voso, MD, for helpful comments on a preliminary version of the article. We acknowledge the generous contribution of Cephalon Europe and TEVA, who provided arsenic trioxide for the entire duration of the study. We thank the following members of the independent review committee for their assessments during the study: W.K. Hofmann of Mannheim University Hospital and A. Hochhaus of Jena University Hospital, Germany. We also thank the following contributors: Laura Di Donato and Sandra De Simone for data collection at the Gruppo Italiano per le Malattie Ematologiche dell'Adulto (GIMEMA) Data Center and Michaela Sauer from the Study Alliance Leukemia (SAL), Alfonso Piciocchi for assistance in statistical analysis (GIMEMA), Claudia Ciardi and Serena Lavorgna (Università Tor Vergata) for technical help in PML-RARA and FLT3 internal tandem duplication molecular analyses, and Brunangelo Falini (Università di Perugia) for kindly donating the PGM3 antibody used in diagnostic screening. Finally, we thank all participants and research staff of all centers within GIMEMA, Acute Myeloid Leukemia Study Group, and SAL.

\section{Appendix}

The following additional authors and centers contributed to the APL0406 trial. Full names, academic degrees, and affiliations are as follows: Istituto di Ematologia, Università Cattolica Sacro Cuore, Rome (Simona Sica, MD); Dipartimento di OncoEmatologia, Ospedale SS Antonio e Biagio, Alessandria (Alessandro Levis, MD); Dipartimento di Ematologia e Oncologia, Fondazione Istituto de Ricovero e Cura a Carattere Scientifico (IRCCS) Policlinico San Matteo and Università di Pavia, Pavia (Mario Cazzola, MD); U.O.C. Ematologia 1, IRCCS A.O.U. San Martino-IST, Genoa (Angelo M. Carella, MD); Dipartimento di Ematologia, Ospedale Niguarda Ca' Granda, Milan (Enrica Morra, MD); Azienda Ospedaliera Pugliese Ciaccio, Catanzaro (Maria Grazia Kropp, MD); Dipartimento di Scienze Mediche e Chirurgiche, Università di Modena e Reggio Emilia, Modena (Mario Luppi, MD); Istituto di Ematologia "Lorenzo A. Seragnoli," Policlinico Sant'Orsola-Malpighi, Università degli Studi di Bologna, Bologna (Giovanni Martinelli, MD); Ematologia, Ospedale Ferrarotto, Università dei Catania, Catania Francesco Di Raimondo, MD); Dipartimento di Emato-oncologia, Azienda Ospedaliera "Bianchi-Melacrino-Morelli," Reggio Calabria (Francesca Ronco, MD); Unità Operativa Complessa di Ematologia, Ospedale S. Eugenio, Roma (Paolo De Fabritiis, MD); Divisione di Ematologia, Policlinico G.B. Rossi, Università degli Studi di Verona, Verona (Giampaolo Nadali, MD); Dipartimento di Scienze Mediche, Sezione di Ematologia e Fisiopatologia dell'Emostasi, Azienda Ospedaliera Universitaria Arcispedale Sant'Anna, Cona, Ferrara (Antonio Cuneo, MD); Complesso Ospedaliero San Giovanni Addolorata, Roma (Anna Chierichini, MD); Unità di Ematologia e Trapianti, I.F.O. Istituto Nazionale Tumori Regina Elena, Roma (Andrea Mengarelli, MD); Unità Operativa Complessa di Ematologia e Terapia Cellullare, Ospedale C. e G. Mazzoni, Ascoli Piceno (Piero Galieni, MD); Dipartimento di Medicina Interna, Azienda Ospedaliera Universitaria-Policlinico G. Martino, Università di Messina, Messina (Caterina Musolino, MD); Divisione di Ematologia, Ospedale Santa Maria Goretti, Latina (Giuseppe Cimino, MD); Divisione di Ematologia, Ospedale S. Camillo, Roma (Leonardo Pacilli, MD); Clinica Ematologica e Centro Trapianti e Terapie Cellulari, Azienda Ospedaliera-Universitaria di Udine, Udine (Renato Fanin, MD); Dipartimento di Scienze Biologiche, Medicina Interna 2, Ospedale S. Luigi Gonzaga, Orbassano (Daniela Cilloni, MD); Dipartimento Oncologico, Ospedale S. Maria delle Croci, Ravenna (Eliana Zuffa, MD); Medicina Interna I, Ospedale di Circolo, Varese (Leonardo Campiotti, MD); Dipartimento di Ematologia e Trapianto di Midollo, Istituto Scientifico San Raffaele, Milan (Fabio Ciceri, MD); Divisione di Ematologia TERE, Ospedale Cardarelli, Napoli (Olimpia Finizio, MD) in Italy. Klinikum Nord Nürnberg, Nürnberg (Kerstin Schäfer-Eckart, MD); Robert Bosch Krankenhaus Stuttgart, Stuttgart (Walter Aulitzky, MD); Friedrich-Alexander-Universität Erlangen, Erlangen (Stefan Krause, MD); Ev. Diakonie-Krankenhaus gGmbH Bremen, Bremen (Johannes Kullmer, MD); Klinikum der Johannes Gutenberg Universität Mainz, Mainz (Markus Radsak, MD); Universitätsklinikum Essen, Essen (Ulrich Dührsen, MD); Klinikum rechts der Isar, München, München (Katharina Götze, MD); Universitätsmedizin Göttingen, Göttingen (Gerald Wulf, MD); Helios Klinikum Wuppertal, Wuppertal (Aruna Raghavachar, MD); Caritas-Krankenhaus Lebach, Lebach (Stephan Kremers, MD); Landeskrankenhaus Salzburg, Salzburg (Richard Greil, MD); Charitè-Campus Virchow Klinikum Berlin, Berlin (Jörg Westermann, MD); Universitätsklinikum Bonn, Bonn (Marie von Lilienfeld-Toal, MD) in Germany. 


\begin{tabular}{|c|c|c|c|c|c|c|c|c|}
\hline \multicolumn{8}{|l|}{$\begin{array}{l}\text { Randomly } \\
\text { Assigned }\end{array}$} & Outcome \\
\hline ATRA-ATO & 1 & Investigations & ECG OT prolonged & ATO & Related & ATRA & Related & Recovered \\
\hline ATRA-ATO & 2 & Infections & Pneumonia & ATO & Related & ATRA & Related & Recovered \\
\hline ATRA-ATO & 2 & $\begin{array}{l}\text { Respiratory, thoracic, } \\
\text { and mediastinal } \\
\text { disorders }\end{array}$ & Respiratory failure & ATO & Related & ATRA & Related & Unchanged \\
\hline ATRA-ATO & 3 & Investigations & ALT increased & ATO & Related & ATRA & Related & Recovered \\
\hline ATRA-ATO & 4 & $\begin{array}{l}\text { Respiratory, thoracic, } \\
\text { and mediastinal } \\
\text { disorders }\end{array}$ & $\begin{array}{l}\text { APL differentiation } \\
\text { syndrome }\end{array}$ & ATO & Related & ATRA & Related & Recovered \\
\hline ATRA-ATO & 5 & $\begin{array}{l}\text { Nervous system } \\
\text { disorders }\end{array}$ & $\begin{array}{l}\text { Cerebrovascular } \\
\text { accident }\end{array}$ & ATO & Related & ATRA & Related & Recovered \\
\hline ATRA-ATO & 6 & $\begin{array}{l}\text { Respiratory, thoracic, } \\
\text { and mediastinal } \\
\text { disorders }\end{array}$ & Dyspnea & ATO & Unrelated & - & - & Recovered \\
\hline ATRA-ATO & 7 & $\begin{array}{l}\text { Respiratory, thoracic, } \\
\text { and mediastinal } \\
\text { disorders }\end{array}$ & Respiratory failure & ATO & Unrelated & - & - & Recovered \\
\hline ATRA-ATO & 8 & Cardiac disorders & Pericarditis & ATO & Unrelated & ATRA & Unrelated & Recovered \\
\hline ATRA-ATO & 9 & $\begin{array}{l}\text { Injury poisoning and } \\
\text { procedural } \\
\text { complications }\end{array}$ & $\begin{array}{l}\text { Maternal exposure } \\
\text { before pregnancy }\end{array}$ & ATO & Unrelated & - & - & Recovered \\
\hline ATRA-ATO & 10 & Hepatobiliary disorders & Hepatotoxicity & ATO & Related & ATRA & Related & Recovered \\
\hline ATRA-ATO & 11 & $\begin{array}{l}\text { Nervous system } \\
\text { disorders }\end{array}$ & Cerebral hemorrhage & ATO & Related & ATRA & Related & - \\
\hline ATRA-ATO & 12 & Vascular disorders & Intracranial aneurysm & ATO & Unrelated & ATRA & Unrelated & Unchanged \\
\hline ATRA-ATO & 13 & Investigations & ALT increase & ATO & Related & ATRA & Related & Recovered \\
\hline ATRA-ATO & 13 & Investigations & AST increase & ATO & Related & ATRA & Related & Recovered \\
\hline ATRA-ATO & 14 & GI disorders & Dyspepsia & ATO & Related & - & - & Recovered \\
\hline ATRA-ATO & 14 & $\begin{array}{l}\text { Respiratory, thoracic, } \\
\text { and mediastinal } \\
\text { disorders }\end{array}$ & $\begin{array}{l}\text { APL differentiation } \\
\text { syndrome }\end{array}$ & ATO & Not assessable & - & - & Recovered \\
\hline ATRA-ATO & 15 & Eye disorders & Diplopia & ATO & Not assessable & ATRA & Not assessable & Recovered \\
\hline ATRA-ATO & 16 & Psychiatric disorders & Confusional state & ATO & Unrelated & - & - & Recovered \\
\hline ATRA-ATO & 17 & Hepatobiliary disorders & Hypertransaminasemia & ATO & Related & ATRA & Related & Recovered \\
\hline ATRA-ATO & 18 & Infections & Catheter site infection & ATO & Unrelated & - & - & Recovered \\
\hline ATRA-ATO & 19 & Infections & Pneumonia & ATO & Unrelated & ATRA & Unrelated & Recovered \\
\hline ATRA-ATO & 20 & $\begin{array}{l}\text { General disorders and } \\
\text { administration site } \\
\text { conditions }\end{array}$ & Pyrexia & ATO & Unrelated & ATRA & Unrelated & - \\
\hline ATRA-ATO & 21 & Hepatobiliary disorders & Hepatic failure & ATO & Related & ATRA & Related & Recovered \\
\hline ATRA-ATO & 21 & $\begin{array}{l}\text { Respiratory, thoracic, } \\
\text { and mediastinal } \\
\text { disorders }\end{array}$ & $\begin{array}{l}\text { APL differentiation } \\
\text { syndrome }\end{array}$ & ATO & Related & ATRA & Related & Recovered \\
\hline ATRA-ATO & 22 & Infections & Herpes zoster & - & Related & - & Related & Recovered \\
\hline ATRA-ATO & 22 & $\begin{array}{l}\text { Nervous system } \\
\text { disorders }\end{array}$ & Hydrocephalus & ATO & Related & ATRA & Related & Unchanged \\
\hline ATRA-ATO & 22 & $\begin{array}{l}\text { Skin and subcutaneous } \\
\text { tissue disorders }\end{array}$ & $\begin{array}{l}\text { Leukocytoclastic } \\
\text { vasculitis }\end{array}$ & ATO & Unrelated & ATRA & Unrelated & Recovered \\
\hline ATRA-ATO & 23 & $\begin{array}{l}\text { Respiratory, thoracic, } \\
\text { and mediastinal } \\
\text { disorders }\end{array}$ & Pneumonia & ATO & Unrelated & ATRA & Unrelated & Fatal \\
\hline ATRA-ATO & 24 & $\begin{array}{l}\text { Respiratory, thoracic, } \\
\text { and mediastinal } \\
\text { disorders }\end{array}$ & Dyspnea & ATO & Unrelated & - & - & Recovered \\
\hline ATRA-ATO & 25 & $\begin{array}{l}\text { Nervous system } \\
\text { disorders }\end{array}$ & Depression & - & - & - & - & Recovered \\
\hline ATRA-ATO & 26 & $\begin{array}{l}\text { Respiratory, thoracic, } \\
\text { and mediastinal } \\
\text { disorders }\end{array}$ & Retinoic acid syndrome & ATO & Related & ATRA & Related & Recovered \\
\hline ATRA-ATO & 27 & Cardiac disorders & Syncope & ATO & Unrelated & ATRA & Unrelated & Recovered \\
\hline ATRA-ATO & 27 & Hepatobiliary disorders & Cholelithiasis & ATO & Unrelated & ATRA & Related & Recovered \\
\hline ATRA-ATO & 27 & Investigations & $\begin{array}{l}\text { Hepatic enzyme } \\
\text { increased }\end{array}$ & ATO & Related & ATRA & Related & Recovered \\
\hline ATRA-ATO & 27 & $\begin{array}{l}\text { Musculoskeletal and } \\
\text { connective tissue } \\
\text { disorders }\end{array}$ & Fracture & ATO & Unrelated & ATRA & Unrelated & Recovered \\
\hline ATRA-ATO & 28 & Infections & Catheter site infection & ATO & Unrelated & - & - & Recovered \\
\hline \multicolumn{9}{|c|}{ (continued on following page) } \\
\hline
\end{tabular}


Table A1. Hematologic Toxicity (continued)

\begin{tabular}{|c|c|c|c|c|c|c|c|c|}
\hline $\begin{array}{l}\text { Randomly } \\
\text { Assigned } \\
\text { Treatment }\end{array}$ & UPN & System, Organ, Class & Preferred Term & Drug 1 & Relationship 1 & Drug 2 & Relationship 2 & Outcome \\
\hline ATRA-ATO & 29 & Investigations & $\begin{array}{l}\text { C-reactive protein } \\
\text { increased }\end{array}$ & ATO & Related & - & - & Recovered \\
\hline ATRA-ATO & 29 & $\begin{array}{l}\text { Respiratory, thoracic, } \\
\text { and mediastinal } \\
\text { disorders }\end{array}$ & Dyspnea & ATO & Related & - & - & Recovered \\
\hline ATRA-ATO & 30 & Infections & Febrile infection & ATO & Related & ATRA & Related & Recovered \\
\hline ATRA-ATO & 30 & $\begin{array}{l}\text { Reproductive system } \\
\text { and breast disorders }\end{array}$ & Endometriosis & ATO & Unrelated & ATRA & Unrelated & Recovered \\
\hline ATRA-ATO & 31 & Cardiac disorders & $\begin{array}{l}\text { Acute myocardial } \\
\text { infarction }\end{array}$ & ATO & Unrelated & ATRA & Unrelated & Recovered \\
\hline ATRA-ATO & 32 & Investigations & ECG OT prolonged & ATO & Related & - & - & Recovered \\
\hline ATRA-CHT & 33 & $\begin{array}{l}\text { Respiratory, thoracic, } \\
\text { and mediastinal } \\
\text { disorders }\end{array}$ & $\begin{array}{l}\text { Acute respiratory } \\
\text { distress syndrome }\end{array}$ & IDA & Related & ATRA & Related & Fatal \\
\hline ATRA-CHT & 34 & Cardiac disorders & Myocardial ischemia & IDA & Related & ATRA & Related & Recovered \\
\hline ATRA-CHT & 35 & $\begin{array}{l}\text { Respiratory, thoracic, } \\
\text { and mediastinal } \\
\text { disorders }\end{array}$ & Respiratory failure & IDA & Related & ATRA & Related & Fatal \\
\hline ATRA-CHT & 35 & $\begin{array}{l}\text { Respiratory, thoracic, } \\
\text { and mediastinal } \\
\text { disorders }\end{array}$ & Retinoic acid syndrome & IDA & Related & ATRA & Related & Fatal \\
\hline ATRA-CHT & 36 & Cardiac disorders & $\begin{array}{l}\text { Acute myocardial } \\
\text { infarction }\end{array}$ & IDA & Unrelated & ATRA & Unrelated & Recovered \\
\hline ATRA-CHT & 37 & Investigations & $\begin{array}{l}\text { Aminotransferases } \\
\text { increased }\end{array}$ & IDA & Unrelated & ATRA & Unrelated & Unchanged \\
\hline ATRA-CHT & 38 & $\begin{array}{l}\text { Blood and lymphatic } \\
\text { system disorders }\end{array}$ & Febrile neutropenia & MTX & Related & ATRA & Related & Recovered \\
\hline ATRA-CHT & 39 & GI disorders & Pancreatitis acute & ATRA & Unrelated & - & - & Recovered \\
\hline ATRA-CHT & 40 & $\begin{array}{l}\text { Nervous system } \\
\text { disorders }\end{array}$ & Ischemic stroke & IDA & Related & ATRA & Related & Fatal \\
\hline ATRA-CHT & 41 & Cardiac disorders & Pericarditis & IDA & Related & ATRA & Related & Improved \\
\hline ATRA-CHT & 42 & Cardiac disorders & Cardiac failure & IDA & Related & ATRA & Related & Recovered \\
\hline ATRA-CHT & 43 & $\begin{array}{l}\text { General disorders and } \\
\text { administration site } \\
\text { conditions }\end{array}$ & Pyrexia & MTX & Related & ATRA & Related & Recovered \\
\hline ATRA-CHT & 44 & $\begin{array}{l}\text { Blood and lymphatic } \\
\text { system disorders }\end{array}$ & Febrile neutropenia & MTX & Related & ATRA & Related & - \\
\hline ATRA-CHT & 45 & $\begin{array}{l}\text { Blood and lymphatic } \\
\text { system disorders }\end{array}$ & Bone marrow failure & MTX & Related & ATRA & Related & Improved \\
\hline ATRA-CHT & 46 & $\begin{array}{l}\text { Respiratory, thoracic, } \\
\text { and mediastinal } \\
\text { disorders }\end{array}$ & Pulmonary embolism & - & - & - & Not assessable & Improved \\
\hline ATRA-CHT & 46 & $\begin{array}{l}\text { Respiratory, thoracic, } \\
\text { and mediastinal } \\
\text { disorders }\end{array}$ & Retinoic acid syndrome & - & - & ATRA & Related & Improved \\
\hline ATRA-CHT & 46 & Vascular disorders & Shock hemorrhagic & IDA & Unrelated & ATRA & Unrelated & Fatal \\
\hline ATRA-CHT & 47 & Infections & Bronchopneumonia & - & - & ATRA & Related & Fatal \\
\hline ATRA-CHT & 48 & Vascular disorders & Thrombosis & IDA & Related & ATRA & Related & Recovered \\
\hline ATRA-CHT & 48 & Infections & Bronchopneumonia & MTX & Related & - & - & Fatal \\
\hline ATRA-CHT & 49 & $\begin{array}{l}\text { Blood and lymphatic } \\
\text { system disorders }\end{array}$ & Febrile neutropenia & IDA & Related & ATRA & Related & Recovered \\
\hline ATRA-CHT & 50 & $\begin{array}{l}\text { Blood and lymphatic } \\
\text { system disorders }\end{array}$ & Neutropenia & MTX & Related & ATRA & Related & Recovered \\
\hline ATRA-CHT & 50 & Infections & Pneumonia & MTX & Related & ATRA & Related & Recovered \\
\hline ATRA-CHT & 51 & $\begin{array}{l}\text { General disorders and } \\
\text { administration site } \\
\text { conditions }\end{array}$ & Mucosal inflammation & IDA & Related & ATRA & Related & Recovered \\
\hline ATRA-CHT & 51 & Vascular disorders & Pulmonary embolism & - & Unrelated & - & - & Fatal \\
\hline ATRA-CHT & 52 & GI disorders & Inguinal hernia & MP & Unrelated & MTX & Unrelated & Recovered \\
\hline ATRA-CHT & 53 & $\begin{array}{l}\text { Blood and lymphatic } \\
\text { system disorders }\end{array}$ & Febrile neutropenia & MTX & Related & ATRA & Related & Improved \\
\hline ATRA-CHT & 53 & $\mathrm{Gl}$ disorders & Anal hemorrhage & MTX & Related & ATRA & Related & Recovered \\
\hline ATRA-CHT & 53 & $\begin{array}{l}\text { Injury poisoning and } \\
\text { procedural } \\
\text { complications }\end{array}$ & $\begin{array}{l}\text { Maternal exposures } \\
\text { before pregnancy }\end{array}$ & ATRA & Unrelated & MP & Unrelated & Recovered \\
\hline ATRA-CHT & 54 & $\begin{array}{l}\text { Blood and lymphatic } \\
\text { system disorders }\end{array}$ & Febrile neutropenia & - & Related & - & - & Recovered \\
\hline \multicolumn{9}{|c|}{ (continued on following page) } \\
\hline
\end{tabular}


Platzbecker et al

\begin{tabular}{|c|c|c|c|c|c|c|c|c|}
\hline $\begin{array}{l}\text { Randomly } \\
\text { Assigned } \\
\text { Treatment }\end{array}$ & UPN & System, Organ, Class & Preferred Term & Drug 1 & Relationship 1 & Drug 2 & Relationship 2 & Outcome \\
\hline ATRA-CHT & 54 & $\begin{array}{l}\text { Blood and lymphatic } \\
\text { system disorders }\end{array}$ & Febrile neutropenia & IDA & - & ATRA & - & Recovered \\
\hline ATRA-CHT & 54 & Vascular disorders & Extradural hematoma & IDA & Unrelated & ATRA & Unrelated & Improved \\
\hline ATRA-CHT & 55 & $\begin{array}{l}\text { Respiratory, thoracic, } \\
\text { and mediastinal } \\
\text { disorders }\end{array}$ & Retinoic acid syndrome & IDA & Related & ATRA & Related & Improved \\
\hline ATRA-CHT & 56 & Infections & Urinary tract infection & IDA & Unrelated & ATRA & Unrelated & Recovered \\
\hline ATRA-CHT & 57 & $\begin{array}{l}\text { Blood and lymphatic } \\
\text { system disorders }\end{array}$ & Febrile neutropenia & MTX & Related & ATRA & Related & Recovered \\
\hline ATRA-CHT & 58 & $\begin{array}{l}\text { General disorders and } \\
\text { administration site } \\
\text { conditions }\end{array}$ & Pyrexia & MP & Related & - & - & Recovered \\
\hline ATRA-CHT & 58 & Infections & Bacteremia & IDA & Related & ATRA & Related & Recovered \\
\hline ATRA-CHT & 58 & Infections & Infection & MP & Related & - & - & Recovered \\
\hline ATRA-CHT & 58 & Infections & Infection & MTX & Related & ATRA & Related & Recovered \\
\hline ATRA-CHT & 59 & Cardiac disorders & $\begin{array}{l}\text { Ejection fraction } \\
\text { decreased }\end{array}$ & $\mathrm{MP}+\mathrm{MTX}$ & Unrelated & ATRA & Unrelated & Unchanged \\
\hline ATRA-CHT & 60 & Infections & Sepsis & IDA & Related & ATRA & Related & Recovered \\
\hline ATRA-CHT & 61 & Cardiac disorders & Pericarditis & IDA & Related & - & - & Unchanged \\
\hline ATRA-CHT & 61 & $\begin{array}{l}\text { General disorders and } \\
\text { administration site } \\
\text { conditions }\end{array}$ & Mucosal inflammation & MTX & Related & ATRA & Related & Recovered \\
\hline ATRA-CHT & 61 & $\begin{array}{l}\text { Respiratory, thoracic, } \\
\text { and mediastinal } \\
\text { disorders }\end{array}$ & Respiratory failure & - & - & - & - & Recovered \\
\hline ATRA-CHT & 62 & GI disorders & Diarrhea & ATRA & Unrelated & - & - & Recovered \\
\hline ATRA-CHT & 62 & GI disorders & Emesis & ATRA & Unrelated & - & - & Recovered \\
\hline ATRA-CHT & 63 & $\begin{array}{l}\text { General disorders and } \\
\text { administration site } \\
\text { conditions }\end{array}$ & Fever in aplasia & IDA + MTX & Related & ATRA & Related & Recovered \\
\hline ATRA-CHT & 64 & Infections & Sepsis & IDA & Unrelated & ATRA & Unrelated & Recovered \\
\hline ATRA-CHT & 64 & Investigations & Hyperglycemia & MTX, MP & Unrelated & ATRA & Unrelated & Recovered \\
\hline ATRA-CHT & 64 & $\begin{array}{l}\text { Blood and lymphatic } \\
\text { system disorders }\end{array}$ & Febrile neutropenia & MTX & Related & ATRA & Related & Recovered \\
\hline ATRA-CHT & 65 & Cardiac disorders & Tachyarrhythmia & Prednisone & Unrelated & ATRA & Unrelated & Recovered \\
\hline ATRA-CHT & 65 & Infections & Pneumonia & Prednisone & Related & ATRA & Related & Recovered \\
\hline
\end{tabular}

